\title{
Multivariable Control for a Three-Phase Rectifier Based on Deadbeat Algorithm
}

\author{
Jaime Rohten •, Pericle Zanchetta •, Marco Rivera^, Javier Muñoz^, José Espinoza•, José Silva• \\ * Department of Electrical and Electronic Engineering, Universidad del Bio-Bío, Concepción, Chile, Tel.: +56(41) 3111566. \\ - Department of Electrical and Electronic Engineering, University of Nottingham, U.K. \\ - Department of Industrial Technologies, Universidad de Talca, Chile, Tel.: +56 (75) 2201746. \\ - Electrical Engineering Department, University of Concepción, Chile, Tel: +56(41) 2203512. \\ JRohten@ubiobio.cl,Pericle.Zanchetta@nottingham.ac.uk,marcoriv@utalca.cl,jamunoz@utalca.cl,jose.espinoza@udec.cl,jsilvac@udec.cl
}

\begin{abstract}
This paper presents a deadbeat control technique applied in a voltage source rectifier to regulate both the $d c$ voltage (active power) and reactive power injected to the grid. As the deadbeat control is based on the system model, it leads to a faster response, without overshoot and no need to tune the controller parameters. Hence, it is used to fully control the voltage source rectifier, achieving a fast dynamic response for both the $d c$ voltage and the power factor at the point of connection. However, there are some issues related to the high amount of power required to reach the references -especially in the $d c$ voltage- in a few control steps. The proposed technique also protects the equipment by limiting the maximum power drained to/from the source. The mathematical development is made as a function of the converter power in order to limit it, but at the same time tracking the references with high dynamics, characteristic typical of deadbeat control.
\end{abstract}

Keywords—Deadbeat Control; Voltage Source Rectifier.

\section{INTRODUCTION}

Power converters have given significant solutions to the actual industry, providing accurate control of power, voltage and current, in low, medium and high power applications [1], [2]. However, power converters -voltage and current sourceexhibit a nonlinear behavior, which complicates the mathematical analysis and their control. Therefore, many control techniques have been developed in order to manage the currents and voltages of power electronic devices [3] - [6]. Despite linear controllers have been already designed for power converters, nonlinear control fits better for these nonlinear systems [7] - [12].

Among recently introduced control techniques, model based predictive control has been successfully applied to power converters, because the model and -consequently- its behavior can be easily found by using the Kirchhoff laws. Finite Control Set-Model Predictive Control (FS-MPC), for example, is based on predicting the system behavior using all possible converter available states and applying at the next sampling time the one that minimizes a specific cost function [8], [9]. However, there are other techniques -also based on predictive control- that do not use all possible cases to reach the references [7], [10], among them, the deadbeat control [13]-[16].

This paper proposes a novel deadbeat method applied to active rectifiers based on the voltage source converter. Deadbeat control is a technique with significant advantages as fast dynamic response, because it tries to track the references as soon as the model allows, i.e. the reference will be reached depending on the systems order. Traditionally, deadbeat controller is implemented only for current control [9], [11], [12]. This work however suggests a deadbeat approach for the control of whole system in a multivariable configuration, replacing the conventional linear control for the $d c$ voltage.

The employed topology uses a three-phase converter with an $R L$ input filter, which allows to boost the voltage from the $a c$ side to the $d c$ side, which in turn contributes with a second order dynamic in the current behavior. In addition, a $d c$ capacitor is included to storage the power taken from the $a c$ side and to maintain a desired $d c$ voltage level, giving an additional dynamic. Thus, it can be seen that the whole system has a third order response; then, theoretically, the reference can be reached in three sampling steps at most.

Regardless the deadbeat control theory, there are some concerns related to nonlinear power converters, one of them is related with the saturation due to the maximum voltage that can be injected by the power converter, limited by the $d c$ voltage. On the other hand, the maximum power that can be requested by the rectifier is limited by the maximum current that the $R L$ input filter and the switches may bear. Therefore, a power control is also recommended if a deadbeat controller is implemented [9].

Thus, a deadbeat strategy is introduced, based on the power control in order to attain the advantages of quick response and minimum overshoot provided by the deadbeat technique, but at the same time protecting the system from overpower. The aforementioned issues entail a control algorithm based on the system model, with the aim to control the $d c$ voltage and the power factor using the active and reactive power, respectively, which in turn gives the current references. 


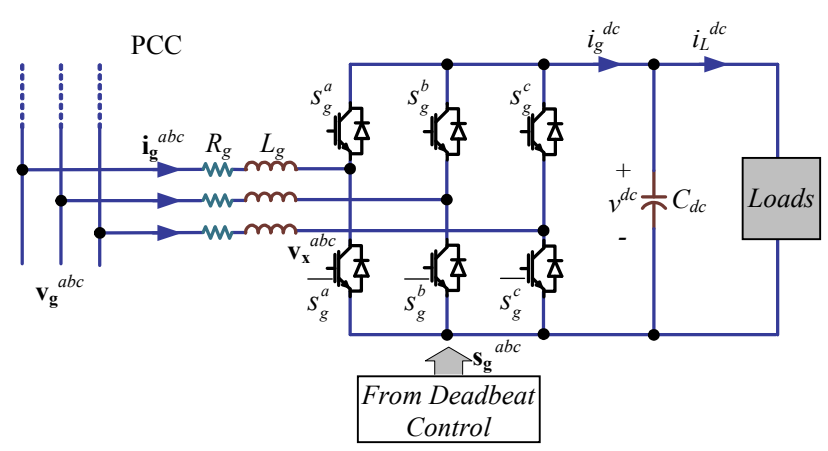

Fig. 1. Power Converter System.

Once the current references are established -by the power control and the supply voltage- the converter voltage is selected -based on the model- and synthetized by a space vector modulation technique. The results show the fast dynamic and the minimum overshoot obtained with this technique. Furthermore, the resulting algorithm is easy to implement in a digital environment; thus, the whole analysis is performed in the discrete domain in order to facilitate the digital implementation.

\section{POWER CONVERTER MODEL}

\section{A. abc Reference Frame Model}

The three-phase Active Front End (AFE) topology used in this work is shown in Fig. 1, where the $R L$ input filter imposes the current dynamics and the $d c$ capacitor the $d c$ voltage dynamics. The voltage Kirchhoff law in the $a c$ side leads to:

$$
\mathbf{v}_{\mathbf{g}}{ }^{a b c}=L_{g} d \mathbf{i}_{\mathbf{g}}{ }^{a b c} / d t+R_{g} \mathbf{i}_{\mathbf{g}}{ }^{a b c}+\mathbf{v}_{\mathbf{x}}{ }^{a b c},
$$

and formulating the current Kirchhoff law on the $d c$ side:

$$
C_{d c} d v^{d c} / d t=i_{g}{ }^{d c}-i_{L}{ }^{d c} .
$$

where the current and voltage through the power converter is:

$$
\mathbf{v}_{\mathbf{x}}{ }^{a b c}=\mathbf{s}_{\mathbf{g}}{ }^{a b c} v^{d c}, i_{g}{ }^{d c}=\mathbf{s}_{\mathbf{g}}{ }^{a b c} \mathbf{i}^{\mathbf{g} a b c}
$$

\section{B. $\alpha \beta$ Reference Frame Model}

The model can be transformed to the $\alpha \beta$ reference frame, in order to reduce the number of equations, for balanced systems. The transformation used is given by:

$$
\mathbf{x}^{\alpha \beta}=\sqrt{\frac{2}{3}}\left[\begin{array}{ccc}
1 & -1 / 2 & -1 / 2 \\
0 & \sqrt{3} / 2 & -\sqrt{3} / 2
\end{array}\right] \mathbf{x}_{a b c},
$$

where $\mathbf{x}^{a b c}$ and $\mathbf{x}^{\alpha \beta}$ represent the variable in $a b c$ and $\alpha \beta$ reference frames, respectively. Therefore, the power converter model can be rewritten with the fobllowing equations:

$$
\begin{gathered}
\mathbf{v}_{\mathbf{g}}{ }^{\alpha \beta}=L_{g} d \mathbf{i}_{\mathbf{g}}{ }^{\alpha \beta} / d t+R_{g} \mathbf{i}_{\mathbf{g}}{ }^{\alpha \beta}+\mathbf{v}_{\mathbf{x}}{ }^{\alpha \beta}, \\
C_{d c} d v^{d c} / d t=\mathbf{s}_{\mathbf{g}}{ }^{\alpha \beta} \mathbf{i}_{\mathbf{g}}{ }^{\alpha \beta}-i_{L}{ }^{d c} .
\end{gathered}
$$

\section{Discrete Time Modeling}

For digital implementation, it is recommended to discretize the power converter model in order to use these equations on the control design. The most used discretization method is performed through the Euler approximation, and given by:

$$
d x(t) / d t \approx(x(k+1)-x(k)) / T_{s},
$$

where $x$ represents the discretized derivate approximation, and $T_{s}$ the sampling time. Therefore, the power converter model can be rewritten, using (7), in the discrete form as:

$$
\begin{gathered}
\mathbf{v}_{\mathbf{g}}{ }^{\alpha \beta}(k)=L_{g} \frac{\mathbf{i}_{\mathbf{g}}{ }^{\alpha \beta}(k+1)-\mathbf{i}_{\mathbf{g}}{ }^{\alpha \beta}(}{T_{s}}+R_{\mathbf{g}} \mathbf{i}_{\mathbf{g}}{ }^{\alpha \beta}(k)+\mathbf{v}_{\mathbf{x}}{ }^{\alpha \beta}(k), \\
C_{d c} \frac{v^{d c}(k+1)-v^{d c}(}{T_{s}}=\mathbf{s}_{\mathbf{x}}{ }^{\alpha \beta}(k) \mathbf{i}_{\mathbf{g}}{ }^{\alpha \beta}(k)-i_{L}{ }^{d c}(k) .
\end{gathered}
$$

\section{DEADBEAT CONTROL}

The aim of the control study is to manage the $d c$ voltage and the power factor at the Point of Common Coupling (PCC). Both of them are related to the power consumed by the converter which, in fact, tie the $a c$ power to the $d c$ power.

\section{A. Desired Voltage Injected by the Converter}

The voltage injected by the rectifier named $\mathbf{v}_{\mathbf{x}}$ can be calculated from (8) as:

$$
\mathbf{v}_{\mathbf{x}}{ }^{\alpha \beta}(k)=\mathbf{v}_{\mathbf{g}}{ }^{\alpha \beta}(k)-L_{g} \frac{\mathbf{i}_{\mathbf{g}}{ }^{\alpha \beta}(k+1)-\mathbf{i}_{\mathbf{g}}{ }^{\alpha \beta}(}{T_{s}}-R_{g} \mathbf{i}_{\mathbf{g}}{ }^{\alpha \beta}(k)
$$

where $\mathbf{i}_{\mathbf{g} \alpha \beta}(k+1)$ can be established as the current reference imposing a given $\mathbf{v}_{\mathbf{x} \alpha \beta}(k)$ to reach this reference in one step ahead. However, due to the impossibility to apply the voltage $\mathbf{V}_{\mathbf{x} \alpha \beta}(k)$ at time $k$, because of the intrinsic computing delay, the expression (10) must be one step forwarded leading to:

$$
\begin{aligned}
\mathbf{v}_{\mathbf{x}}^{\alpha \beta}(k+1)= & \hat{\mathbf{v}}_{\mathbf{g}}{ }^{\alpha \beta}(k+1)+\cdots \\
& -L_{g} \frac{\mathbf{i}_{\mathbf{g}}^{\alpha \beta}(k+2)-\hat{\mathbf{i}}_{\mathbf{g}}{ }^{\alpha \beta}(k+1)}{T_{s}}-R_{g} \hat{\mathbf{i}}_{\mathbf{g}}^{\alpha \beta}(k+1)
\end{aligned}
$$

where the current reference is now given by $\mathbf{i}_{\mathrm{g} \alpha \beta}(k+2)$.

On the other hand, a couple of new variables are necessary to calculate $\mathbf{v}_{\mathbf{x}}^{\alpha \beta}(k+1)$. First, an estimation of the current $\mathbf{i}_{\mathbf{g} \alpha \beta}(k$ $+1)$ can be calculated from (8) as:

$$
\begin{aligned}
\hat{\mathbf{i}}_{\mathbf{g}}^{\alpha \beta}(k+1)= & \left(1-T_{s} R_{g} / L_{g}\right) \mathbf{i}_{\mathbf{g}}^{\alpha \beta}(k)+\cdots \\
& \left(T_{s} / L_{g}\right)\left(\mathbf{v}_{\mathbf{g}}{ }^{\alpha \beta}(k)-\mathbf{s}_{\mathbf{g}}{ }^{\alpha \beta}(k) v^{d c}(k)\right)
\end{aligned}
$$

Second, an estimation of the grid voltage $\mathbf{v}_{\mathbf{g} \alpha \beta}(k+1)$ can be calculated as $\hat{\vec{v}}_{g}(k+1)=e^{j 2 \pi f_{g} T_{s}} \vec{v}_{g}(k)$, leading to:

$$
\hat{\mathbf{v}}_{\mathbf{g}}{ }^{\alpha \beta}(k+1)=\left[\begin{array}{l}
v_{g}{ }^{\alpha}(k) \cos \left(\omega T_{s}\right)-v_{g}{ }^{\beta}(k) \sin \left(\omega T_{s}\right) \\
v_{g}{ }^{\alpha}(k) \sin \left(\omega T_{s}\right)+v_{g}{ }^{\beta}(k) \cos \left(\omega T_{s}\right)
\end{array}\right]
$$

Voltage $\mathbf{v}_{\mathbf{x}}(k+1)$ is a function of the current reference $\mathbf{i}_{\mathbf{g}}(k+2)$, which in turn are imposed by $(i)$ the active power that charges/discharges the $d c$ capacitor, and (ii) the reactive power, which fixes the power factor at the PCC.

\section{B. Current References}

The power supplied by the grid can be separated in active and reactive components, expressed as: 


$$
\begin{aligned}
& p_{g}(k)=\operatorname{Re}\left\{\vec{v}_{g}(k) \vec{i}^{*}(k)_{g}\right\} \\
& =v_{g}{ }^{\alpha}(k) \cdot i_{g}{ }^{\alpha}(k)+v_{g}{ }^{\beta}(k) \cdot i_{g}{ }^{\beta}(k), \\
& q_{g}(k)=\operatorname{Im}\left\{v_{g}(k) i_{g}^{*}(k)\right\} \\
& =v_{g}{ }^{\beta}(k) \cdot i_{g}{ }^{\alpha}(k)-v_{g}{ }^{\alpha}(k) \cdot i_{g}{ }^{\beta}(k){ }^{\prime}
\end{aligned}
$$

where $\vec{v}_{g}$ represents the voltage phasor and $\vec{i}_{g}^{*}$ represents the current conjugate phasor as:

$$
\vec{v}_{g}(k)=v_{g}{ }^{\alpha}(k)+j v_{g}{ }^{\beta}(k), \quad \vec{i}_{g}^{*}(k)=i_{g}{ }^{\alpha}(k)-j i_{g}{ }^{\beta}(k)
$$

From (14) and (15), the currents are calculated as a function of the grid voltage and the desired active and reactive power as:

$$
\begin{gathered}
i_{g}^{\beta, \text { ref }}(k)=\frac{v_{g}{ }^{\beta}(k) p^{\text {ref }}(k)-v_{g}{ }^{\alpha}(k) q^{\text {ref }}(k)}{\left|\vec{v}_{g}(k)\right|^{2}}, \\
i_{g}{ }^{\alpha, \text { ref }}(k)=\frac{q^{\text {ref }}(k)+v_{g}{ }^{\alpha}(k) i_{g}{ }^{\beta, \text { ref }}(k)}{v_{g}{ }^{\beta}(k)} .
\end{gathered}
$$

Equations (17) and (18) give the current as a function of the desired active and reactive power. However, (11) needs the current references at time $k+2$; therefore, (17) and (18) must be two step forwarded to use them for the current references. On the other hand, when (17) and (18) are forwarded, it is required the voltage $\mathbf{v}_{\mathbf{g} \alpha \beta}(k+2)$ which can be found as:

$$
\hat{\vec{v}}_{g}(k+2)=e^{j 2 \cdot 2 \pi f_{g} T_{s}} \vec{v}_{g}(k),
$$

and the power references should also be found at step $k+2$, leading to:

$$
i_{g}^{\beta, r e f}(k+2)=\frac{v_{g}^{\beta}(k+2) p^{r e f}(k+2)-v_{g}{ }^{\alpha}(k+2) q^{r e f}(k+2)}{\left|\vec{v}_{g}(k+2)\right|^{2}}
$$

$$
i_{g}^{\alpha, r e f}(k+2)=\frac{q^{r e f}(k+2)+v_{g}{ }^{\alpha}(k+2) i_{g}^{\beta}{ }^{\beta, e f}(k+2)}{v_{g}^{\beta}(k+2)} .
$$

\section{Power References}

The power references can be separated in $(i)$ the active power reference, defined by the active power consumed by the AFE, and (ii) the injection of the reactive power, defined by the power factor. The active power consumed by the AFE is separated between $(a)$ the $d c$ power, to charge/discharge the $d c$ capacitor and the power consumed by the load $v^{d c} i_{L}{ }^{d c}$, and $(b)$ the amount of power dissipated by the $R L$ input filter. Thus, $(a)$ the $d c$ active power can be written as:

$$
p^{d c}(t)=\frac{1}{2} C_{d c} \frac{d\left(v^{d c}(t)\right)}{d t}+v^{d c}(t) \cdot i_{L}^{d c}(t) .
$$

or in the discrete form:

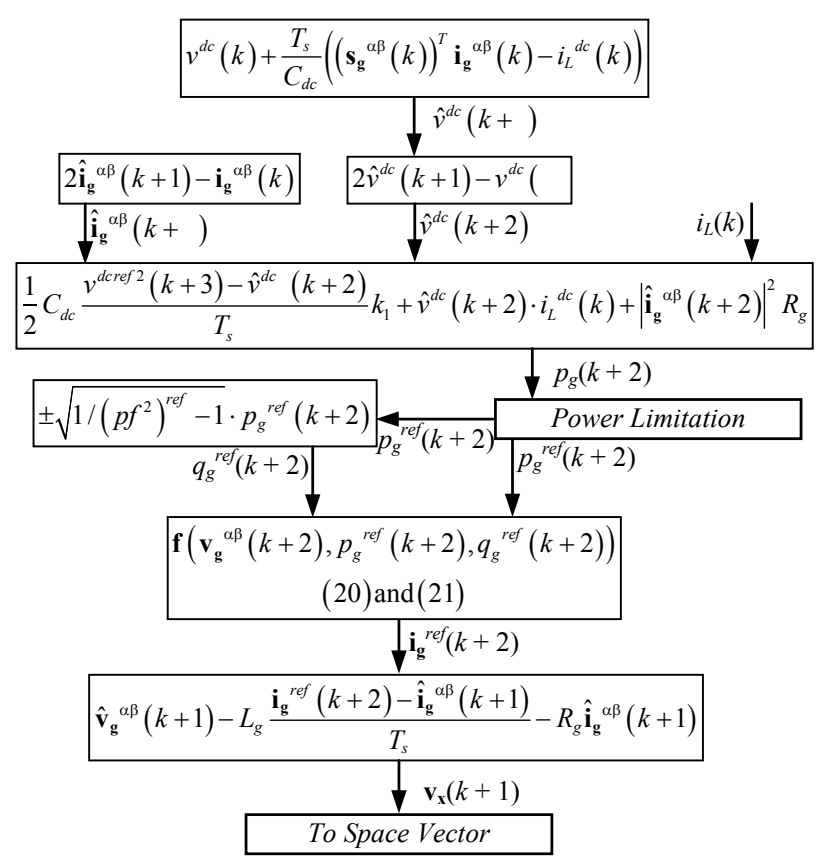

Fig. 2. Power Converter Control Algorithm.

$$
p^{d c}(k)=\frac{1}{2} C_{d c} \frac{v^{d c 2}(k+1)-v^{d c}(}{T_{s}}+v^{d c}(k) \cdot i_{L}^{d c}(k)
$$

and $(b)$ the power used by the first order $R L$ input filter is expressed as:

$$
p_{R L}(k)=\operatorname{Re}\left\{\left(\vec{v}_{g}(k)-\vec{v}_{x}(k)\right) \vec{i}_{g}^{*}(k)\right\},
$$

where the voltage $\vec{v}_{g}(k)-\vec{v}_{x}(k)$ can be written as:

$$
\vec{v}_{g}(k)-\vec{v}_{x}(k)=\vec{z}_{g} \vec{i}_{g}(k),
$$

with $\vec{z}_{g}=R_{g}+j L_{g}$. Therefore, the power $p_{R L}$ is now defined as:

$$
\begin{aligned}
& p_{R L}(k)=\operatorname{Re}\left\{\vec{z}_{g} \vec{i}_{g}(k) \vec{i}_{g}^{*}(k)\right\}=\operatorname{Re}\left\{\vec{z}_{g}\left|\vec{i}_{g}(k)\right|\right\} \\
&=\left|\vec{i}_{g}(k)\right|^{2} \operatorname{Re}\left\{\vec{z}_{g}\right\}=\left|\vec{i}_{g}(k)\right|^{2} R_{g}
\end{aligned}
$$

Consequently, the active power required by the AFE is:

$$
p^{r e f}(k+2)=p^{d c}(k+2)+p_{R L}(k+2),
$$

this equation is two step forwarded to achieve the desired reference required by (20) and (21). As (27), and therefore (23) is two step forwarded, the voltage $v^{d c}(k+3)$ is defined as the $d c$ voltage reference and the voltage $\hat{v}^{d c}(k+2)$ needs to be estimated. A prediction of $v^{d c}$ can be found using (9) as:

$$
\hat{v}^{d c}(k+1)=v^{d c}(k)+\frac{T_{s}}{C_{d c}}\left(\left(\mathbf{s}_{\mathbf{g}}{ }^{\alpha \beta}(k)\right)^{T} \mathbf{i}_{\mathbf{g}}{ }^{\alpha \beta}(k)-i_{L}^{d c}(k)\right)
$$

From (28) it is easy to note that if this equation is again one step forwarded -to obtain $v^{d c}(k+2)$ - it will be necessary to 


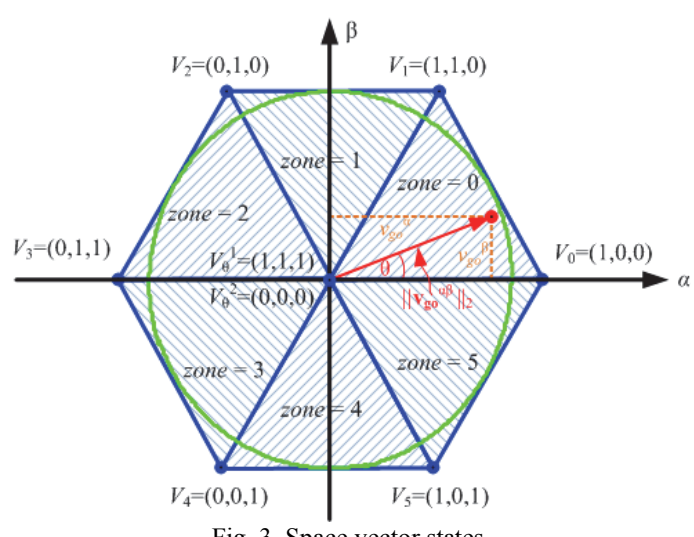

Fig. 3. Space vector states.

include: $(i) i_{L}(k+1)$ which normally is defined as a disturbance, being this prediction a difficult task, then it is considered the following approximation $\hat{i}_{L}(k+2) \approx \hat{i}_{L}(k+1)=i_{L}(k)$, (ii) the switching state at step $k+1$, which is not feasible because this variable is the controller output, (11). Consequently, to overcome this problem, $\hat{v}^{d c}(k+2)$ is estimated as:

$$
\hat{v}^{d c}(k+2)=\hat{v}^{d c}(k+1)+\Delta v^{d c}(k+1) .
$$

where $\Delta v^{d c}(k+1)=\hat{v}^{d c}(k+1)-v^{d c}($

On the other hand, the reactive power reference is set as a function of the power factor $p f$ and the desired active power, then, the equation is defined as:

$$
q_{g}^{r e f}(k+2)= \pm \sqrt{1 /\left(p f^{2}\right)^{r e f}-1} \cdot p_{g}{ }^{r e f}(k+2) .
$$

\section{Effects of the Fast Imposed Dynamic}

Deadbeat Control has important advantages as the fast response, and the minimum overshoot. Furthermore, the desired voltage can be achieved in three steps and the power factor in two steps from (20), (21) and (27). However, three steps for the $d c$ link voltage controller is too fast to be accomplished, because the amount of energy to charge/discharge the $d c$ capacitor may be significant. Therefore, it is important to limit this amount of power to protect the rectifier of high currents, which may damage the components. On the other hand, the power converter has a natural saturation point given by the maximum $\mathbf{v}_{\mathbf{x}}$ voltage which is related to the $d c$ link voltage.

Thus, two equations are adapted in order to ensure a slower dynamic response. First, the equation that gives the $d c$ active power is rewritten as:

$$
p^{d c}(k)=\frac{1}{2} C_{d c} \frac{v^{d c 2}(k+1)-v^{d c 2}(k)}{T_{s}} k_{1}+v^{d c}(k) \cdot i_{L}^{d c}(k)
$$

where $k_{1}$ is placed to reduce the amount of power required by the first term in (31). This constant also allows to smooth the dynamic response, because it reduces the noise influence on the power reference. This harmful effect is amplified because the voltage is squared and divided by $T_{s}$. Then, it is important to include $k_{1}$ for noisy variables.
The second equation given by (27) needs to be limited in order to reduce the maximum reference current in (20) and (21) . Therefore, the final algorithm states that if $p^{r e f}>p_{\max }$, then $p^{\text {ref }}$ $=p_{\max }$; and if $p^{r e f}<-p_{\max }$, then $p^{r e f}=-p_{\max }$. The whole control algorithm is presented in Fig. 2.

\section{Voltage Synthetization}

Once the voltage $\mathbf{v}_{\mathbf{x}}$ is defined by the deadbeat control, it must be synthetized by a modulation technique, [12]. Space Vector is chosen to achieve the requested voltage $\mathbf{v}_{\mathbf{x}}$ provided by the deadbeat control. The range of voltages that the modulating strategy is capable to generate can be seen in Fig. 3 , limited by the $d c$ link voltage and the eight valid states. Thus, any voltage $\mathbf{v}_{\mathbf{x}}$ inside the hatched region can be achieved with the three nearest voltages (one of them the zero state). Thus the voltage $\mathbf{v}_{\mathbf{x}}$ is synthetized as,

$$
T_{s} \mathbf{V}_{\mathbf{x}}^{\alpha \beta}=\mathbf{V}_{i}^{\alpha \beta} v^{d c} T_{1}+\mathbf{V}_{i+1}^{\alpha \beta} v^{d c} T_{2}+\mathbf{V}_{\theta}^{\alpha \beta}\left(T_{s}-T_{1}-T_{2}\right),
$$

where $\mathbf{V}_{\theta}$ represents the zero state and $i$ represents the zone where the vector $\mathbf{v}_{\mathbf{x}}$ is, Fig. 3. Therefore, each state is applied during the following times:

$$
\begin{aligned}
& T_{1}=\frac{\left(v^{d c} \mathbf{V}_{i+1}^{\alpha \beta}\right)^{\times} \mathbf{V}_{\mathbf{x}}{ }^{\alpha \beta}}{\left(v^{d c} \mathbf{V}_{i+1}^{\alpha \beta}\right) \times\left(v^{d c} \mathbf{V}_{i}^{\alpha \beta}\right)} T_{s}, \\
& T_{2}=\frac{v_{x}^{\alpha}}{v^{d c} V_{i+1}^{\alpha}} T_{s}-\frac{v^{d c} V_{i}^{\alpha}}{v^{d c} V_{+1}^{i}{ }^{\alpha}} T_{1},
\end{aligned}
$$

where $\mathbf{V}_{i}^{\alpha \beta}$ is defined as:

$$
\mathbf{V}_{i}^{\alpha \beta}=\sqrt{2 / 3}[\sin (i \cdot \pi / 3) \cos (i \cdot \pi / 3)]^{T},
$$

Now, in order to decide the zone where the voltage $\mathbf{v}_{\mathbf{x}}$ is placed, Fig. 3, the angle $\theta=\arg \left\{\mathbf{v}_{\mathbf{x} \alpha \beta}(k+1)\right\}$ is calculated as:

$$
\begin{gathered}
\theta=\operatorname{sign}\left(v_{x}{ }^{\beta}(k+1)\right) \cdot \arccos \left(\frac{v_{x}^{\alpha}(k+1)}{\left\|\mathbf{v}_{\mathbf{x}}^{\alpha \beta}(k+1)\right\|_{2}}\right), \\
\text { TABLE I } \\
\text { PARAMETERS }
\end{gathered}
$$

\begin{tabular}{cc}
\hline \hline Parameters & Value \\
\hline$v_{g}$ & $230 \mathrm{~V}, \mathrm{rms}$ \\
$v_{d c}$ & $600 \mathrm{~V}$ \\
$R_{g}$ & $0.4 \Omega$ \\
$L_{g}$ & $4.75 \mathrm{mH}$ \\
$C_{d c}$ & $2.2 \mathrm{mF}$ \\
$R_{d c}$ & $250 \Omega$ \\
$f_{g}$ & $50 \mathrm{~Hz}$ \\
$f_{s}$ & $10 \mathrm{kHz}$ \\
$k_{1}$ & 0.06 \\
\hline \hline
\end{tabular}

\section{RESULTS}

To corroborate the mathematical analysis and the aforementioned algorithm, the topology shown in Fig. 1 is controlled by the presented deadbeat technique and tested under different conditions with the parameters listed in TABLE I. 


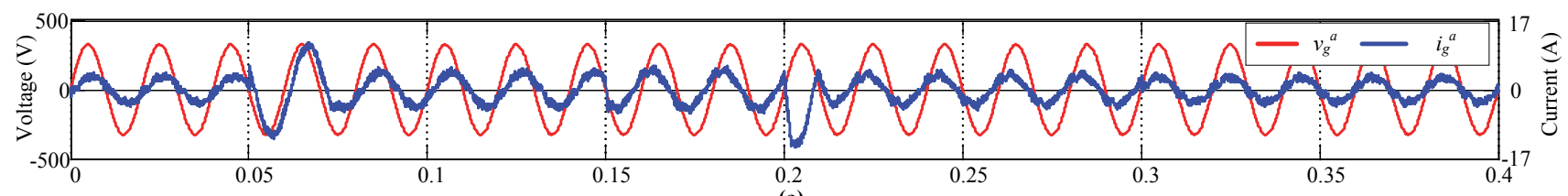

(a)
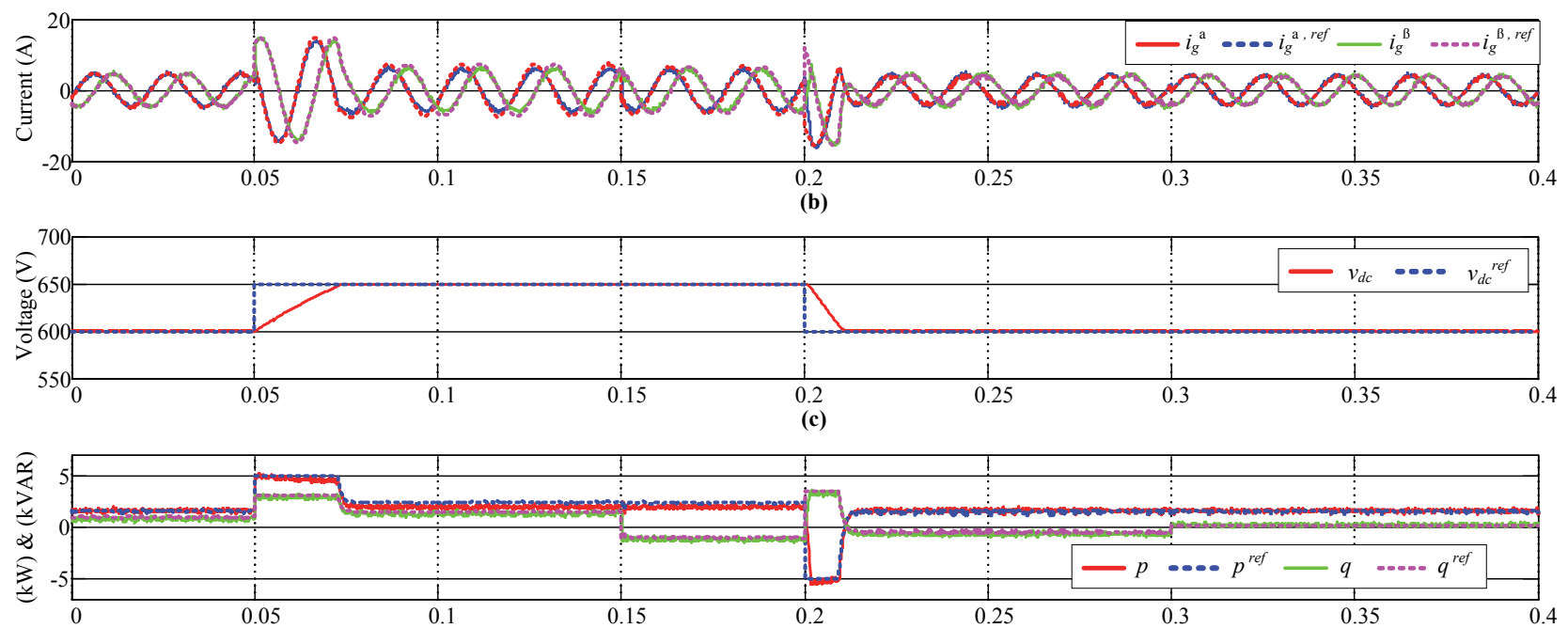

(d)

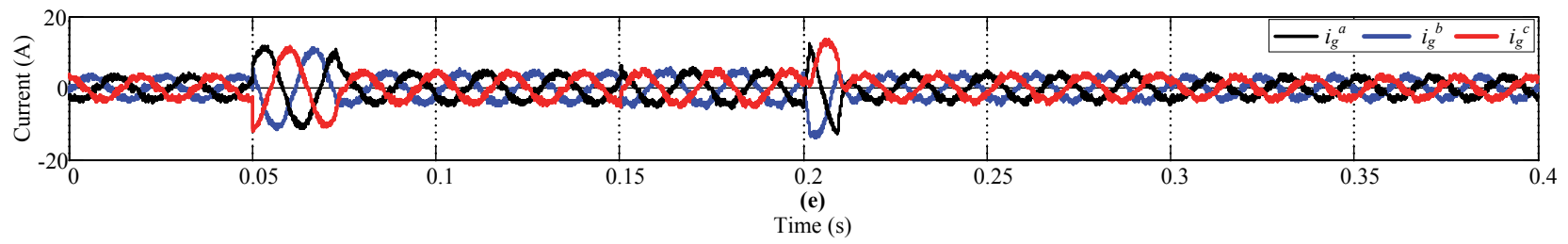

Fig. 4. Power control loops $v^{d c}$ step and reactive power control (a) grid voltage and current, (b) reference and measured $\alpha \beta$ grid current, (c) reference and measured $d c$ voltage, (d) reference and measured active and reactive power, and (e) grid currents $\mathbf{i}_{\mathbf{g}}{ }^{a b c}$.

The designed controller is tested under $d c$ voltage reference step change, Fig. 4. The $d c$ voltage changes from $600 \mathrm{~V}$ to 650 $\mathrm{V}$ in $t=0.05 \mathrm{~s}$ and then it goes back to $600 \mathrm{~V}$ in $t=0.2 \mathrm{~s}$. The results illustrated in Fig. 4 show that the reference is achieved in only $20 \mathrm{~ms}$ approximately for the step up, i.e. one grid cycle, for a $50 \mathrm{~V}$ step change. In addition, it is worth to highlight that no overshoot is presented, which is an advantage of the deadbeat control. On the other hand, the time to reach the reference when it goes down is less than when it goes up, which is mainly due to the losses presented in the inverter, making easier to reduce instead to increase the power stored in the $d c$ capacitor.

Aiming to see the load impact behavior, Fig. 5 shows the system response when the $d c$ current is incremented in a $100 \%$ from $2.4 \mathrm{~A}$. This was obtained inserting a $250 \Omega$ resistor in parallel to $R_{d c}=250 \Omega$. The result shown in Fig. 5 describes that the $d c$ voltage as well as the power factor is maintained in their reference value even with this significant step change, and the deadbeat control imposes higher currents in order to track its references given by the requested load power.

\section{CONClusions}

Deadbeat control is a suitable alternative to control power converters. When this method is applied on this multivariable systems, the time response is significantly reduced, and without

overshoot. On the other hand, and despite the fast response, the maximum amount of power is limited by the same algorithm protecting the equipment of potential damage due to extreme operating conditions. In addition, as the control algorithm is based on the model, it is intuitive once the variables and references are defined.

\section{REFERENCES}

[1] S. Yang, A. Bryant, P. Mawby, D. Xiang, L. Ran and P. Tavner, "An Industry-Based Survey of Reliability in Power Electronic Converters," in IEEE Transactions on Industry Applications, vol. 47, no. 3, pp. 14411451, May-June 2011.

[2] Q. Chen, "Opportunities and challenges to power electronics industry in alternative and renewable energy," Power Electronics Systems and Applications, 2009. PESA 2009. 3rd International Conference on, Hong Kong, 2009, pp. 1-1.

[3] P. Gaur and P. Singh, "Various control strategies for medium voltage high power multilevel converters: A review," Engineering and Computational Sciences (RAECS), 2014 Recent Advances in, Chandigarh, 2014, pp. 16.

[4] P. Kowstubha, K. Krishnaveni and K. Ramesh Reddy, "Review on different control strategies of LLC series resonant converters," Advances in Electrical Engineering (ICAEE), 2014 International Conference on, Vellore, 2014, pp. 1-4.

[5] S. Debnath, J. Qin, B. Bahrani, M. Saeedifard and P. Barbosa, "Operation, Control, and Applications of the Modular Multilevel Converter: A Review," in IEEE Trans. on Power Electron., vol. 30, no. 1, pp. 37-53, Jan. 2015. 


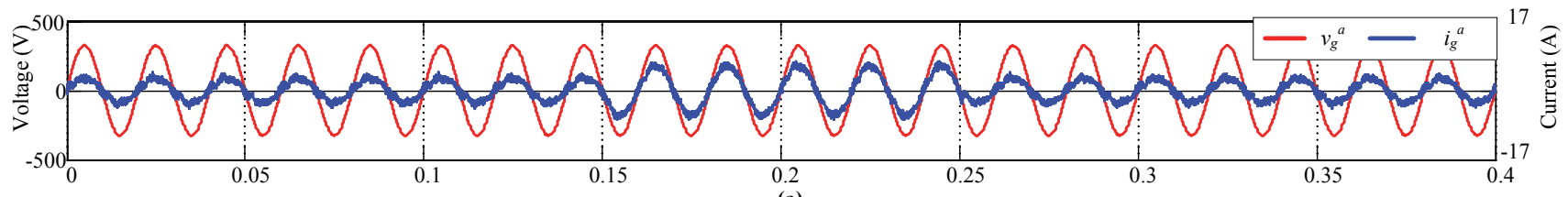

(a)

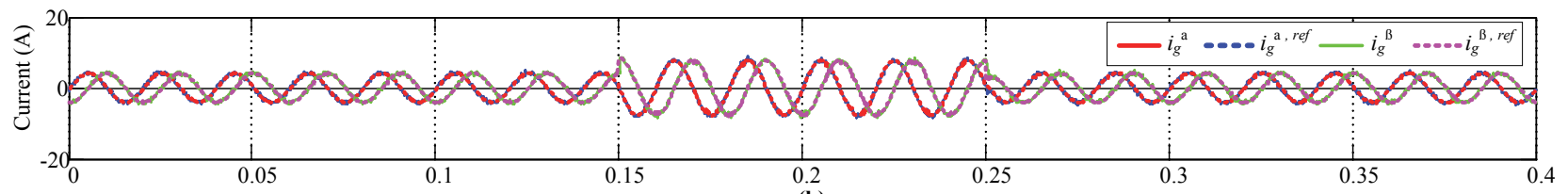

(b)

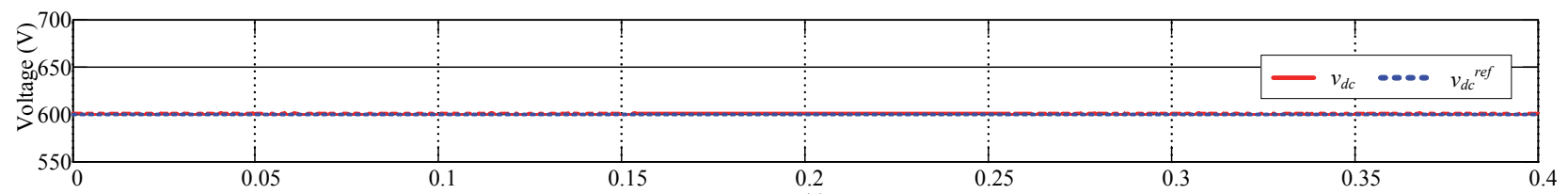

(c)

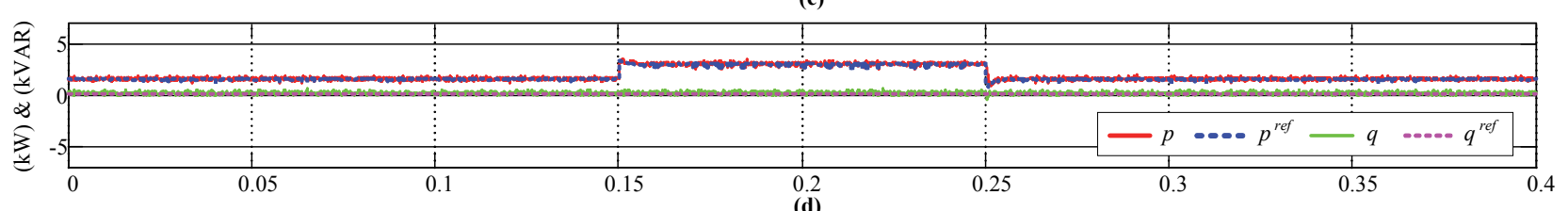

(d)

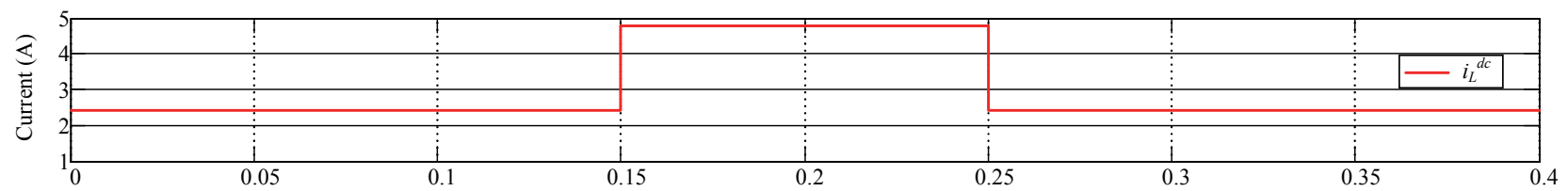

(e)

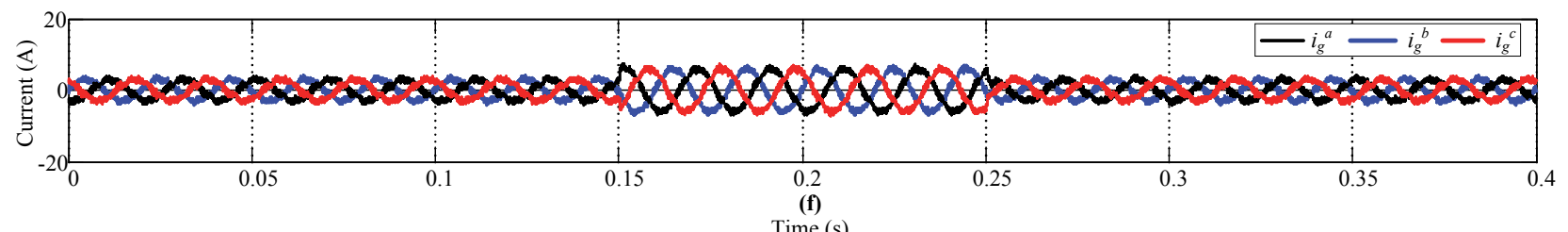

Fig. 5. Step load impact (a) grid voltage and current, (b) reference and measured $\alpha \beta$ grid current, (c) reference and ameasured $d c$ voltage, (d) reference and measured active and reactive power, (e) $d c$ load current $i_{L}{ }_{L}^{a b c}$, and (f) grid currents $\mathbf{i}_{\mathbf{g}}^{a b c}$.

[6] J. Muñoz, J. Rohten, J. Espinoza, P. Melín, C. Baier and M. Rivera, "Review of current control techniques for a cascaded H-Bridge STATCOM," Industrial Technology (ICIT), 2015 IEEE International Conference on, Seville, 2015, pp. 3085-3090.

[7] P. Cortés, M. Kazmierkowski, R. Kennel, D. Quevedo, and J. Rodríguez "Predictive Control in Power Electronics and Drives," IEEE Trans. on Ind. Electron., vol. 55, no 12, pp. 4312-4324, Dic. 2008.

[8] M. Pérez, M. Vásquez, J. Rodríguez, J. Pontt, "FPGA-based predictive current control of a three-phase active front end rectifier", in Conf. Rec. IEEE ICIT'12, pp. 1-6, Feb. 2009.

[9] J. Rohten, J. Espinoza, J. Munoz, D. Sbarbaro, M. Pérez, P. Melin, J. Silva, E. Espinosa, "Enhanced Predictive Control for a Wide Time Variant Frequency Environment" IEEE Trans. on Ind. Electron., vol. PP no 99, pp. 1, Mar. 2016.

[10] Y. Zhang, W. Xie, Y. Zhang, "Deadbeat direct power control of threephase pulse-width modulation rectifiers" IET Power Electronics, vol. 7, no 6, pp. 1340-1346, Nov. 2013.

[11] M. Pérez, M. Vásquez, J. Rodríguez, J. Pontt, "Research on deadbeat Current Control Strategy of Three-Phase PWM Voltage Source Rectifier", in Conf. Rec. IEEE ICIT'12, pp. 1-6, Feb. 2009.
[12] C. Xia, M. Wang, Z. Song, and T. Liu, "Robust Model Predictive Current Control of Three-Phase Voltage Source PWM Rectifier with Online Disturbance Observation" IEEE Trans. on Ind. Informatics, vol. 8, no 3, pp. 459-471, Mar. 2012.

[13] Y. Zhang, W. Xie and Y. Zhang, "Deadbeat direct power control of threephase pulse-width modulation rectifiers," in IET Power Electronics, vol. 7, no. 6, pp. 1340-1346, June 2014.

[14] A. Luo, H. Xiao and Z. Shuai, "Double deadbeat-loop control method for distribution static compensator," in IET Power Electronics, vol. 8, no. 7, pp. 1104-1110, 72015.

[15] K. Nishida, T. Ahmed and M. Nakaoka, "Cost-Effective Deadbeat Current Control for Wind-Energy Inverter Application With Filter," in IEEE Trans. on Industry Applications, vol. 50, no. 2, pp. 1185-1197, March-April 2014.

[16] Z. Xueguang, Z. Wenjie, C. Jiaming and X. Dianguo, "Deadbeat Control Strategy of Circulating Currents in Parallel Connection System of ThreePhase PWM Converter," in IEEE Transactions on Energy Conversion, vol. 29, no. 2, pp. 406-417, June 2014. 